\title{
Moral Foundations Theory and the Psychology of Charitable Giving 血国
}

\author{
ARTUR NILSSON ${ }^{1 *}$, ARVID ERLANDSSON $^{1}$ and DANIEL VÄSTFJÄLL ${ }^{1,2}$ \\ ${ }^{1}$ Department of Behavioural Sciences and Learning, Linköping University, Linköping, Sweden \\ ${ }^{2}$ Decision Research, Eugene, Oregon USA
}

\begin{abstract}
Moral foundations theory proposes that intuitions about what is morally right or wrong rest upon a set of universal foundations. Although this theory has generated a recent surge of research, few studies have investigated the real-world moral consequences of the postulated moral intuitions. We show that they are predictably associated with an important type of moral behaviour. Stronger individualizing intuitions (fairness and harm prevention) and weaker binding intuitions (loyalty, authority, and sanctity) were associated with the willingness to comply with a request to volunteer for charity and with the amount of self-reported donations to charity organizations. Among participants who complied with the request, individualizing intuitions predicted the allocation of donations to causes that benefit out-groups, whereas binding intuitions predicted the allocation of donations to causes that benefit the in-group. The associations between moral foundations and self-report measures of allocations in a hypothetical dilemma and concern with helping in-group and out-group victims were similar. Moral foundations predicted charitable giving over and above effects of political ideology, religiosity, and demographics, although variables within these categories also exhibited unique effects on charitable giving and accounted for a portion of the relationship between moral foundations and charitable giving. (C) 2020 The Authors. European Journal of Personality published by

John Wiley \& Sons Ltd on behalf of European Association of Personality Psychology
\end{abstract}

Key words: moral intuitions; ideology; charitable giving; prosocial behaviour; helping

Moral psychologists have traditionally defined morality exclusively in terms of liberal values, such as fairness, liberty, and caring for the weak and vulnerable. But many cultures and groups express additional moral concerns, treating, for instance, disloyalty, promiscuity, and rebelliousness as moral infringements. Moral foundations theory (Graham et al., 2013; Graham, Haidt, \& Nosek, 2009; Haidt, 2008; Haidt \& Graham, 2007) therefore offers a pluralist account of morality designed to help us understand the moral psychology of persons and cultures with diverse viewpoints. By defining moral systems in terms of social functions rather than specific values, as 'interlocking sets of values, practices, institutions, and evolved psychological mechanisms that work together to suppress or regulate selfishness and make social life possible' (Haidt, 2008, p. 70), it permits a broader range of the everyday judgments of right and wrong that recur around the world to qualify as 'moral'.

Moral foundations theory proposes that people's intuitions about what is morally right or wrong rest on five (or

*Correspondence to: Artur Nilsson, Department of Behavioural Sciences and Learning, Linköping University, SE-581 83 Linköping, Sweden. E-mail: artur.nilsson@liu.se

This article earned Open Data and Open Materials badges through Open Practices Disclosure from the Center for Open Science: https://osf.io/ tvyxz/wiki. The data are permanently and openly accessible at: Data in .csv format: https://osf.io/49ehm. Data in .sav format: https://osf.io/rebtf. Analysis scripts for main analyses: https://osf.io/b3ywp. Data and scripts for mixed linear models: https://osf.io/8234x. All supplements: https://doi.org/ 10.17605/osf.io/mcwv7. And the materials are permanently and openly accessible at: Materials: https://osf.io/whnp4. All supplements: https://doi. org/10.17605/osf.io/mcwv7. Author's disclosure form may also be found at the Supporting Information in the online version. perhaps more') universal, evolved foundations (Haidt, 2008; Haidt \& Joseph, 2004). The foundations of fairness and caring for others are portrayed as 'individualizing' in the sense that they perform a moral function by virtue of redirecting the agent's focus from selfish desires to the needs and rights of other individuals; they prevail in liberal, individualistic, and secular contexts. The foundations of in-group loyalty, respect for authority, and purity/sanctity are portrayed as 'binding' in the sense that their moral function consists in binding moral agents into roles and duties that make them sacrifice their self-interests for a group, system, or religious cause, which fosters social cohesion and order to the benefit of everyone; they prevail in conservative, collectivist, and religious contexts (Haidt, 2008).

Moral foundations theory has generated a rapidly growing body of work spanning diverse research topics, such as political psychology, attitude change, environmental sustainability, and the psychology of law (Day, Fiske, Downing, \& Trail, 2014; Feinberg \& Willer, 2013; Graham et al., 2009; Silver, 2017). Nevertheless, there is still remarkably little research on how moral foundations are manifested in real-world behaviour, partly due to a traditional split between the study of moral judgment and the study of moral behaviour in moral psychological research (Ellemers, van der Toorn, Paunov, \& van Leeuwen, 2019; Graham et al., 2013; Graham \& Valdesolo, 2018). This is a crucial

\footnotetext{
${ }^{1}$ Moral foundation theorists have been open to the possibility of adding more foundations, such as liberty/oppression, to this taxonomy (Graham et al., 2013).
} 
drawback, because self-report measures of moral inclinations are notoriously susceptible to social desirability biases. Studies suggest, for example, that people's actions often have a surface appearance of morality while serving their self-interest and opposing their explicitly endorsed moral principles (Batson, Kobrynowicz, Dinnerstein, Kampf, \& Wilson, 1997), and moral behaviour in real decision situations can contradict moral choices made in hypothetical decision situations (FeldmanHall et al., 2012; Johansson-Stenman \& Svedsäter, 2012).

In the current research, we therefore applied moral foundations theory to the psychology of charitable giving. Specifically, we investigated whether the distinction between individualizing and binding moral intuitions can help to explain why people donate money to charitable causes that focus on helping in-group and out-group victims in self-report and behavioural data. Charitable giving is undoubtedly a moral behaviour on a functionalist definition of morality, because it typically entails the suppression of purely selfish desires to the benefit of other individuals or groups. But charitable giving generally passes the litmus test of a 'moral' behaviour also on the main normative, philosophical definitions of morality (e.g. consequentialist, deontological, and virtue-ethical), as it is likely to have good consequences and to be congruent with ethical duties and virtues. In fact, charitable giving may be among the most important forms of moral behaviour in a modern world, particularly in highly developed countries, where even donations that do not require noticeable personal sacrifices can have tremendous impact on other people's lives (Singer, 2009).

\section{MORAL FOUNDATIONS THEORY AND CHARITABLE GIVING}

To empirically assess the moral functions of the postulated foundations, it is not enough merely to investigate the relationship between moral intuitions and overall donations to charity. It is also important to consider whether the foundations predict different kinds of charitable giving that are congruent with their respective contents. The most straightforward way to test this is to investigate whether moral intuitions predict which charitable causes people support.

The vast majority of past research on the psychology of charitable giving to date has focused on factors that predict the overall incidence and amount of donations, including personality characteristics, socio-demographic factors, how the charity appeal is framed, the number of solicitations, and contextual factors such as anonymity and potential reputational benefits (Bekkers \& Wiepking, 2011; Zagefka \& James, 2015). Considerably less research has been devoted to increasing our understanding of how donors make their picks from the complex smorgasbord of available charitable causes. As numerous researchers have lamented (Bennett, 2003; Breeze, 2013; Neumayr \& Handy, 2019), this is a severely under-researched question in the psychology of charitable giving.
There are nevertheless a few past studies that give us reason to expect that the selection among causes is guided in part by moral intuitions. For example, an interview study of committed British donors led to the conclusion that personal taste, rather than perceived need, was 'the most salient factor in the selection of charitable beneficiaries' (Breeze, 2013, p. 11). The donors tended to select charities that they found personally appealing, congruent with their interests, and close to their heart. Similarly, several survey studies conducted in the USA and Western Europe (Bennett, 2003; Erlandsson, Björklund, \& Bäckström, 2017; Grey Matter Research, 2011; Hawkins \& Nosek, 2012; Neumayr \& Handy, 2019; Wiepking, 2010) have suggested that personal characteristics, such as values, religious and political orientations, trust, and empathy, play a key role in determining which causes people support. In other words, far from being perfectly rational maximizers of utility, people typically seem to base their decisions about what causes to support more on personal values, passions, interests, and general outlook on life than on calculations of urgency, need, and efficiency.

Although charitable causes can be conceptualized in many ways, the distinction between in-group and out-group causes stands out in terms of being relevant for understanding both charitable giving and moral intuitions. Few other psychological phenomena are more well documented than the human inclination to treat in-group members more favourably than out-group members (see Brewer, 1979; Tajfel \& Turner, 1979, for classical theoretical perspectives; see Balliet, Wu, \& De Dreu, 2014; Everett, Faber, \& Crockett, 2015, for recent reviews). In-group favourability is a universal phenomenon, rooted in the evolutionary challenge of forming cohesive social coalitions. It recurs across species, but in human beings, it extends beyond close circles of friends, family, and small-scale groups to encompass also more abstract communities bound together by nations, religions, movements, and ideologies. Past studies have found that the psychological processes underlying in-group and out-group helping differ from each other (Stürmer, Snyder, Kropp, \& Siem, 2006; Telzer, Ichien, \& Qu, 2015).

According to moral foundations theory, individualizing intuitions concerning the moral importance of fairness and caring for others shift the focus from the moral agent's selfish desires to the suffering and injustice experienced by other individuals (or sentient beings), while binding intuitions concerning the importance of in-group loyalty, respect for authority, and purity/sanctity propel moral agents to sacrifice their self-interests for a group or system (Graham et al., 2009; Haidt, 2007, 2008). In other words, the individualizing intuitions entail an expansion of the moral circle outward and a concern for the welfare of individuals regardless of their group membership, while the binding intuitions pull in the opposite direction towards a circle of moral engagement centred on social collectives, such as family, team, congregation, or nation (Crimston, Bain, Hornsey, \& Bastian, 2016; Graham, Waytz, Meindl, Iyer, \& Young, 2017).

Several predictions can be derived from this theoretical account. The binding moral intuitions should, insofar as they 
foster a concern with in-group victims, stimulate donations and allocations of donations to charitable causes in a manner contingent upon whether the causes are likely to benefit in-group members or strengthen in-group systems. The individualizing intuitions should, insofar as they foster a concern about helping other human beings that is impartial with respect to the group membership of the victims, stimulate more donations to charitable causes in general. This impartiality with respect to the victims should in turn make donors with individualizing moral intuitions more inclined to allocate donations to out-group causes compared with donors with less of these intuitions, insofar as the latter group exhibits the ubiquitous human tendency to primarily help in-group victims (Zagefka \& James, 2015). An individualizing impartiality between out-group and in-group victims might, in this sense, serve as a counterweight to an instinctual 'default-mode' moral parochialism.

The central predictions are thus that (i) persons with individualizing moral intuitions are more inclined to donate to charity in general compared with persons with less of these intuitions (i.e. individualizing intuitions predict charitable giving in general); (ii) donors with individualizing moral intuitions are more inclined to allocate donations to causes that focus on helping out-group victims compared with donors with less of these intuitions (i.e. individualizing intuitions predict allocation to out-group causes); and (iii) donors with binding moral intuitions are more inclined to allocate donations to causes that focus on helping in-group victims compared with donors with less of these intuitions (i.e. binding intuitions predict allocation to in-group causes).

There is some previous support for these suggestions. Nilsson, Erlandsson, and Västfjäll (2016) found that binding moral intuitions predicted lower self-reported donations to international aid, which focuses directly on helping out-group members, and less intentions to donate to out-group members, but they predicted higher self-reported donations to medical research, which is likely to benefit the in-group. Individualizing moral intuitions predicted higher self-reported donations to international aid but not medical research, more intentions to donate to out-group members, and higher donations overall. However, with respect to actual donation behaviour, the binding intuitions turned out to predict lower donations whereas the individualizing intuitions predicted higher donations even when the charity ad focused on in-group medical care.

A key limitation of this research is that it did not separate the decision about whether to donate or not from the selection among charitable causes, as each participant was presented with just one charity advertisement. To be able to take differences in what causes people prefer into consideration, it is necessary to give participants the opportunity to select among causes and to disentangle the act of selecting a cause from the overall incidence and amount of donations. In addition, most of the participants in these studies were in their 20s, although medical causes may have greater moral urgency among older persons (Neumayr \& Handy, 2019; Srnka, Grohs, \& Eckler, 2003).

\section{THE ROLE OF POLITICAL AND RELIGIOUS ORIENTATIONS}

Binding moral intuitions are robustly associated with right-wing (or conservative) political orientation and higher religiosity, while individualizing intuitions are associated with a left-wing (or liberal) political orientation (Graham \& Haidt, 2010; Graham et al., 2009). It is conceivable that moral foundations influence charitable giving solely by virtue of these associations, given that political and religious orientations have well-documented effects on charitable giving (Bekkers \& Wiepking, 2011; Brooks, 2007; Wiepking $\&$ Bekkers, 2012). Although Nilsson et al. (2016) found effects of moral foundations on charitable giving when controlling for general religious identification and left-right self-placement, it is possible that specific ideological preferences or aspects of religiosity matter more for in-group and out-group giving.

The relationships between political ideology, religious orientation, and charitable giving are complex. Right-wingers are less likely than left-wingers to value prosociality (Piurko, Schwartz, \& Davidov, 2011), and they may be particularly negatively disposed to engage in charitable giving insofar as they view the world as a just and meritocratic place, where people get what they deserve (Furnham, 1995). On the other hand, right-wingers may be more inclined to engage in charitable giving insofar as they hold the libertarian belief that individuals rather than governments should have the responsibility for solving social problems (Brooks, 2007; Kemmelmeier, Jambor, \& Letner, 2006). Furthermore, right-wing ideology is intertwined with religion in many countries, and religious practices are associated with increased charitable giving (Bekkers \& Wiepking, 2011; Brooks, 2007; Zagefka \& James, 2015), particularly in countries that lack strong secular institutions and social safety nets (Norenzayan, Henrich, \& Slingerland, 2013). By contrast, in a post-industrial welfare state such as Sweden, where the left-right conflict predominantly concerns issues pertaining to equality and redistribution rather than traditional values, social change, or religiosity (Aspelund, Lindeman, \& Verkasalo, 2013; Nilsson et al., 2020), charitable giving is likely to be more prevalent on the left than on the right overall (Nilsson et al., 2016).

There is evidence to suggest that political ideology is linked to in-group versus out-group giving as well. For instance, studies have suggested that left-wingers donate more to international and human rights causes and less to veterans and religious causes than right-wingers do (Grey Matter Research, 2011; Nilsson et al., 2016; Wiepking, 2010), and liberals express greater moral concern towards friends relative to family and towards the world relative to the nation than conservatives do (Waytz, Iyer, Young, Haidt, \& Graham, 2019). On the broadest scale, left-right divergences in political orientation can be described in terms of a distinction between resistance to (vs. advocacy of) social change and preference for social and economic equality (vs. acceptance of inequality; Jost, Glaser, Kruglanski, \& Sulloway, 2003). This distinction converges with the 
distinction between binding and individualizing moral foundations, in the sense that preference for equality entails an impartial concern for the well-being of all individuals while resistance to change involves protection of in-group traditions and norms (Federico, Weber, Ergun, \& Hunt, 2013; Nilsson \& Erlandsson, 2015; Nilsson et al., 2020).

The evidence bearing on religious prosociality towards in-groups and out-groups is less clear. Some studies suggest that religiosity exclusively promotes in-group donations, while others find that it predicts donations also to secular causes (Brooks, 2007; Norenzayan et al., 2013). One possibility is that the form religiosity takes matters. For instance, because religiously based charitable giving is driven in part by the sheer amount of solicitations religious individuals encounter in their daily lives (Bekkers \& Wiepking, 2011; Nilsson et al., 2016), and people are likely to receive solicitations from in-groups (e.g. a local congregation), it is possible that traditional religiosity is associated particularly with in-group giving. Modern forms of spirituality, on the other hand, incorporate beliefs and feelings that may be particularly likely to stimulate out-group giving, including the sense that all life is interconnected and that everyone has a responsibility for the lives of other sentient beings (Piedmont, 1999). Tradition-oriented religiousness and subjective spirituality have proved to be fundamentally different dimensions with different personality correlates (Saucier \& Skrzypińska, 2006).

\section{OVERVIEW OF RESEARCH}

Using both behavioural and self-report measures of charitable giving and a heterogeneous sample of 985 Swedish adults, we tested the hypotheses that (i) individualizing moral intuitions predict greater charitable giving overall (to both in-groups and out-groups), (ii) individualizing moral intuitions predict allocation of donations to charitable causes that focus on helping out-group victims, and (iii) binding moral intuitions predict allocation to charitable causes that focus on helping in-group victims. These hypotheses were not pre-registered, but they were derived from moral foundations theory (Graham et al., 2009; Haidt, 2008) and introduced in a previous paper (Nilsson et al., 2016) published prior to the current research. We also performed exploratory analyses to determine which aspects of moral intuitions (binding and individualizing), political ideology (resistance to change, preference for equality, libertarianism, just-world beliefs, and left-right self-placement), religion (traditional religiosity and spirituality), and demographics (gender, age, and education) have independent effects on charitable giving, as well as which of the individualizing and binding foundations (harm, fairness, loyalty, authority, and purity/sanctity) matter the most.

We used a behavioural measure of donation allocations to in-group-focused and out-group-focused charity organizations that separated the act of choosing whether to donate or not (and how much to donate) from the act of selecting an organization to allocate the donation to. We also included self-report measures of total amount and incidence of donations to charity, allocation to in-group versus out-group causes in a hypothetical dilemma, and personal concern for helping out-group and in-group victims. This allowed us to assess the convergence of behavioural and self-report measures of charitable giving and the robustness of the findings.

\section{METHOD}

\section{Participants}

We recruited Swedish adults from a nationally representative panel with the help of an independent research firm. The participants filled out questionnaires online. We initially excluded 432 participants who had dropped out of the survey before reaching the end. The survey was completed by 1015 participants. Quota sampling was used to ensure that the total sample of survey completers included approximately the same proportion of participants from different age groups, gender groups, and geographic regions as the total Swedish adult population does. We excluded an additional 30 participants who had completed the entire survey in less than five minutes, after making sure that this did not alter the findings. We confirmed that the characteristics of the final sample $(N=985$ after excluding the 30 participants with extremely fast response times) were similar to the national averages (Statistics Sweden, 2018) in terms of sex, age, education, and party preference (among adults, $\geq 18$ years old). The sample was $49.8 \%$ female, and the mean age was 49.2 years $(S D=15.2)$. Average left-right self-placement was very close to the theoretical midpoint of the scale, $t(984)=1.08, p=.28$. All participants were Swedish citizens who spoke Swedish fluently.

Power analyses conducted in G*Power 3.1 (Faul, Erdfelder, Lang, \& Buchner, 2007) indicated that the final sample gave us $80 \%$ power (two-tailed) to detect effects of a predictor in a regression model corresponding to $\rho= \pm .089$ (analyses involving the full sample: $n=985$ ) and $\rho= \pm .116$ (analyses involving only those who chose to volunteer: $n=584$ ) with a $5 \%$ alpha level. The same power analyses conducted with a more stringent alpha level of $0.36 \%$ (5\% divided by 14 , which is the total number of statistical hypotheses we tested with Holm-Bonferroni corrections, see Table S7, https://osf.io/whnp4) yielded estimates of $\rho= \pm .120$ and $\rho= \pm .156$, respectively. These are the lower and upper bounds of effects pertaining to our main hypotheses that we had at least $80 \%$ power to detect. The estimates were identical when the models were specified to include one predictor and when they were specified to include 14 predictors, which was the maximum number of predictors in our models. The effects of moral intuitions on charitable giving reported by Nilsson et al. (2016) were generally at least this large.

Two of our statistical hypotheses concerned statistical interactions. Power calculations for repeated measures analysis in $\mathrm{G}^{*}$ Power indicated that we would have $80 \%$ power ( $n=985, r=.19$ between repeated measures) to detect 2 (between $) \times 2$ (within) interaction effects ranging from $\rho= \pm .057$ (5\% alpha level) to $\rho= \pm .076(0.36 \%$ alpha level $)$. 


\section{Measures}

All questionnaire items were translated into Swedish and adjusted through back-translations either in the current research or in earlier studies. The materials are openly accessible in Supporting Information (pp. 10-20, https://osf.io/whnp4).

\section{Volunteering behaviour}

All participants first completed a survey that included measures of moral intuitions, religiosity, political orientation, hypothetical allocation decisions, and cognitive dispositions (results regarding cognitive dispositions have been presented in Erlandsson, Nilsson, Tinghög, \& Västfjäll, 2018, and Nilsson, Erlandsson, \& Västfjäll, 2019). After participants had completed the initial survey, which took most of them at least 10 minutes, we measured their volunteering behaviour by asking them whether they would be willing to fill in a 'a few extra questions' for charity (59.3\% responded yes) rather than skipping directly to the final questions. The participants were informed that their choice would be completely anonymous and that 5 SEK (around 0.50 euro or 50 US cents) would be donated to a charity organization of their choosing if they would fill out the additional questions. Participants who agreed to this were asked to fill out four questions measuring libertarianism before choosing what organization their donations would be allocated to. They were not told in advance how many extra questions they would get to fill out or how long this was estimated to take them.

\section{Allocation behaviour}

The participants who had chosen to volunteer were instructed to pick one out of 34 well-known charity organizations that their donation would be allocated to. We recoded the allocation choice into two dichotomous variables representing whether the volunteers selected an in-group organization $(39.9 \%$ of the donors) or not and whether they selected an out-group organization $(38.9 \%$ of the donors) or not. These variables overlap. Because the participants could choose only one organization, choosing an in-group organization entailed not choosing an out-group organization, and vice versa. The in-group category contained 10 organizations, including both well-known medical organizations, such as the Swedish Cancer Fund and the Swedish Heart-Lung Fund, and organizations that provide other kinds of help in Sweden, such as the Sea Rescue Society and the Swedish Salvation Army. The out-group category contained eight well-known organizations, such as the Red Cross, Doctors Without Borders, and SOS International, which are specialized on providing international aid.

This classification has been validated in past studies in terms of the finding that people perceive the organizations as focusing on helping Swedish victims (in-group organizations) or non-Swedish victims (out-group organizations) and the finding that self-reported donations to the two categories of organizations are factorially distinct (Erlandsson, Nilsson, Tinghög, Andersson, \& Västfjäll, 2019; Nilsson et al., 2016). Participants in these validation studies and participants in the current research were recruited from the same nationally representative panel (which contains 20000 individuals in total). Most of the donations that were not allocated to any of the in-group or out-group organizations were allocated to environmental causes, which focus more on non-human victims than on human victims.

\section{Self-reported donations}

The participants indicated whether they had donated to charity organizations or other voluntary sector organizations over the last year (71.8\% responded yes), approximately how much money (in SEK) they had donated to such organizations over the last year $[M=1367, S D=2226$; $M d=500$, interquartile range $(\mathrm{IQR})=1500$, skewness $=2.24]$, and whether they had donated to or otherwise helped street-begging EU migrants (a salient out-group) over the last year $(1=$ not at all; $2=$ yes, once or twice; $3=$ yes, several times; 4 = yes, many times; 5 = yes, every week; $M=1.91$, $S D=1.15, M d=1, \mathrm{IQR}=2$, skewness = 2.42).

\section{Personal charity concerns}

In the final part of the survey, all participants were asked to report their personal concern with respect to different kinds of charitable causes. The instruction read: 'Charity organizations have different areas of activity. Below you will find a list of common areas of activity. Different areas of activity are closest to the heart for different persons. Please indicate how important each of the areas is to you personally.' The participants responded on a 5-point Likert scale $(1=$ not at all important to me; 2 = not very important to me; $3=$ slightly important to me; 4 = important to me; 5 = very important to $m e)$. Six items measured concern for providing help in Sweden $(\alpha=.72 ; M=3.96, S D=0.76, M d=4.00$, $\mathrm{IQR}=1.00$, skewness $=-0.69)$, and six items measured concern for providing help in other countries $(\alpha=.85 ; M=3.27$, $S D=0.85, M d=3.33, \mathrm{IQR}=1.00$, skewness $=-0.40)$. Sample items include 'Social work and fighting poverty in Sweden', 'Treatment and health care for ill children and adults in Sweden', and 'Help and support for refugees in Sweden'. The out-group items were formulated in the same ways, except that 'in Sweden' was replaced by 'in other countries'.

\section{Hypothetical allocation decision}

Participants were instructed to imagine that they worked for a charity organization that fights diseases and that their task was to choose one out of two equally costly charity projects: Project $\mathrm{A}$, which is 'estimated to save the lives of 25 Swedish children suffering from a serious disease', and Project B, which is 'estimated to save the lives of approximately 50 children suffering from a serious disease in African rural areas'. A third of the participants were asked to report what project they would choose, a third of them were asked to report what project they should choose, and the last third were asked to report what is the moral choice. All participants were asked to select one out of four options (e.g. $1=I$ would for sure save the lives of 25 children in Sweden; 2 = I would probably save the lives of 25 children in Sweden; 3 = I would probably save the lives of 50 children in Africa; $4=I$ would for sure save the lives of 50 children in Africa; $M=2.30, S D=0.90)$. The 
should/would/moral choice variations did not make any difference to the results, so we aggregated all responses.

\section{Moral foundations}

We measured moral intuitions with the Moral Foundations Questionnaire (Graham et al., 2009), which has previously been validated in Sweden (Nilsson \& Erlandsson, 2015). It measures each of five foundations - harm $(\alpha=.61)$, fairness ( $\alpha=.59)$, loyalty $(\alpha=.56)$, authority $(\alpha=.67)$, and purity/sanctity $(\alpha=.76)$ - with three items assessing the perceived moral relevance of concerns that rest on the given foundation and three items assessing agreement with moral judgments. The participants responded to the relevance items on a 6-point Likert response bar ranging from 0 (not at all relevant) to 5 (extremely relevant). The judgment items were presented together with the other individual difference scales, all of which included a 7-point Likert response bar ranging from 1 (completely disagree) to 7 (completely agree).

The empirical data from past research (e.g. Davies, Sibley, \& Liu, 2014; Graham et al., 2011; Nilsson \& Erlandsson, 2015; Nilsson et al., 2020) are consistent with a hierarchical model with two superordinate foundations (individualizing and binding intuitions) with underlying facets (harm and fairness; loyalty, authority, and purity/sanctity). At the same time, a recent cross-cultural analysis of the structure of moral foundations across 27 nations indicated that there is substantial overlap between the specific facets of each superordinate factor (i.e. between harm and fairness and between loyalty, authority, and purity/sanctity) but little overlap between the two superordinate factors (Iurino \& Saucier, 2020). In the current research, we relied mainly on scores for individualizing intuitions $(\alpha=.75 ; M=4.53$, $S D=0.76)$ and binding intuitions $(\alpha=.83 ; M=3.59$, $S D=0.76$ ) both because our hypotheses applied to the level of the superordinate factors and because the evidence for the distinctions between specific facets is not clear. But we include exploratory analyses pertaining to the five specific foundations as well to probe the generality of effects of individualizing and binding intuitions on charitable giving.

\section{Political ideology}

Participants reported left-right self-placement $(M=5.06$, $S D=1.74$ ) on a 9-point Likert scale ranging from 1 (very far to the left) to 9 (very far to the right). We measured just-world beliefs by aggregating two four-item sub-scales for justice and controllability $(\alpha=.84 ; M=3.37$, $S D=1.09)$ that were included in the original measure (Janoff-Bulman, 1989). We measured preference for equality $(\alpha=.67 ; M=4.70, S D=1.17)$, resistance to change $(\alpha=.72$; $M=4.13, S D=1.23)$, and libertarianism $(\alpha=.69 ; M=4.52$, $S D=1.09$ ) with four items each (Kahan, 2012; Nilsson \& Jost, 2017; Schwartz, Caprara, \& Vecchione, 2010). The libertarianism scale was filled out only by participants who volunteered to fill in additional questions for charity.

\section{Religious orientation}

We measured traditional religiosity $(\alpha=.77 ; M=2.47$, $S D=1.57, M d=2.00, \mathrm{IQR}=2.50$, skewness $=1.07)$ with one item measuring religious identity with the same 7-point response bar that was used for the other items and one measuring religious activity (for the activity item, the response options ranged from $1=$ never to $7=$ every day). We measured spirituality $(\alpha=.82 ; M=3.75, S D=1.42)$ in terms of a four-item measure of spiritual universalist beliefs (Piedmont, 1999).

\section{Education}

We measured education by asking participants to report the highest level of education they had completed ( 1 = compulsory school not completed, 2 = compulsory school completed, 3 = upper secondary school completed, $4=$ univer sity/college studies started, $5=$ graduated from university/college; $M=3.89, S D=1.06, M d=4, \mathrm{IQR}=2$, skewness $=-0.30)$.

\section{Statistical analyses}

We report associations between moral foundations and outcome variables bearing on our hypotheses with bias-corrected $95 \%$ confidence intervals generated through 10000 bootstrap resamples. Correlations between all predictors (moral foundations, political ideology, religious orientation, and demographics) and outcome variables (self-report and behavioural measures of charitable giving) are reported in Table 1. We quantify associations between two nominal variables in terms of phi coefficients based on chi-squared tests and all other associations in terms of correlations. Because the distributions of scores on variables measuring self-reported amounts of donations, traditional religiosity, and education deviated from normality, the reported correlations involving these variables are Spearman's $(\rho)$ rank-order correlations. All other correlations are Pearson's ( $r$ ) correlations.

We report results of regression analyses predicting each of the outcome variables one by one in terms of all predictors (except for libertarianism, which we excluded from these analyses because this scale was filled out only by the subset of participants who chose to volunteer for charity and it failed to correlate with allocations to in-group and out-group causes). We used logistic regressions for dichotomous outcome variables (having vs. not having volunteered, donated to charity last year, allocated to an in-group cause, and allocated to an out-group cause) and linear least squares regressions for all other outcome variables (amount donated last year, allocations in a hypothetical dilemma, donations to an out-group, and personal charity concerns). For the linear regression analyses, we added demographics, political ideology, and religious orientation in a first step and moral foundations in a second step to test whether the moral foundations contributed to the models over and above the effects of other predictors on charitable giving. For the logistic regressions, we entered all predictors at the same time. We ran all linear and logistic regression analyses once with the individualizing and binding intuitions included among the predictors (results of these analyses are presented in Tables 3 and 5) and once with the five foundations (i.e. harm, fairness, loyalty, authority, and purity/sanctity) included instead of the individualizing and binding sum scores among the 


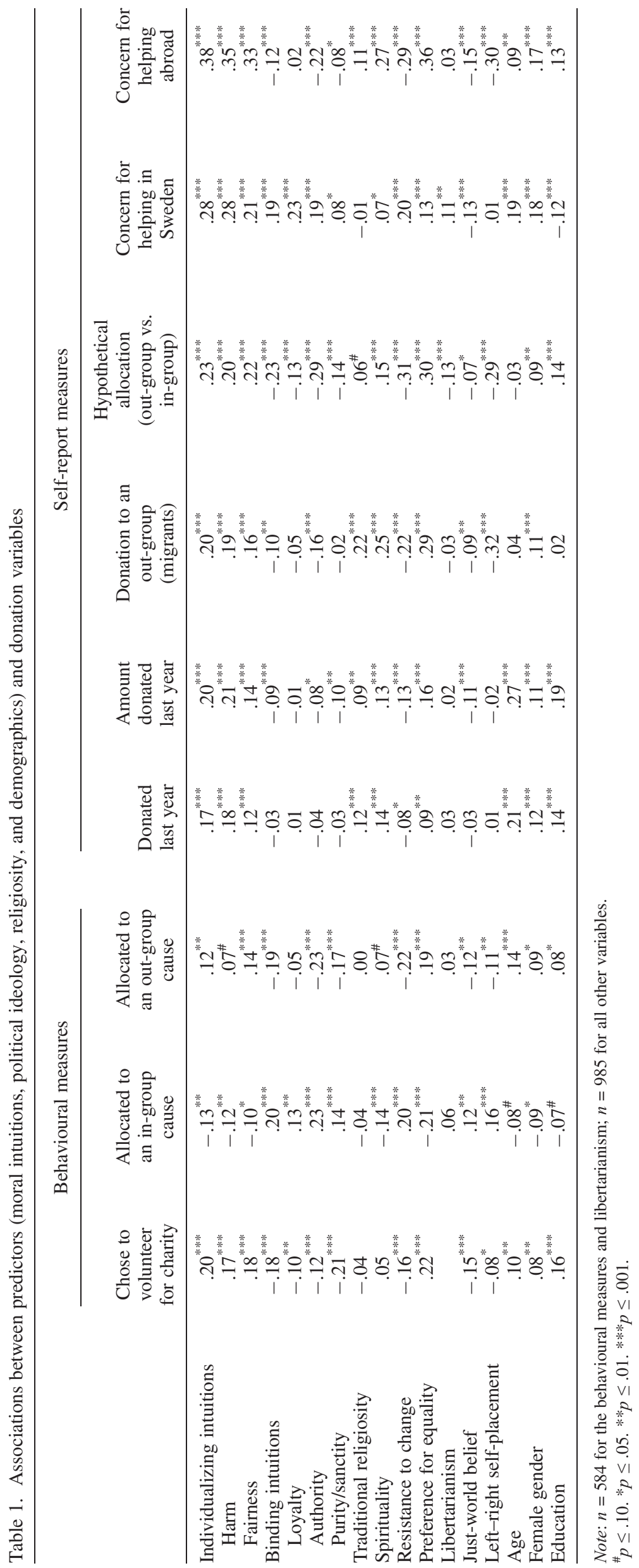


predictors (results of these analyses are presented in Tables 4 and 6).

We report odds ratios from logistic regressions based on standardized scores, which means that they indicate how much a one standard deviation change in a predictor variable changes the odds that a person would donate or allocate donations to the given cause, with $95 \%$ confidence intervals (i.e. $p<.05$ when both ends of the confidence interval are under or over 1). We report standardized regression coefficients from linear regression models with regular $95 \%$ confidence intervals (tolerance $\geq .51$; see also Tables S3 and S4, https://osf.io/whnp4, for fit statistics of models with different groups of predictors included).

Because regression models can be sensitive to skewness and outliers, we tried using a logarithmic transformation to reduce the skewness of self-reported out-group donations, and we tried reducing outliers on self-reported amount donated to two different maximum values. We also investigated whether excluding predictors with distributions that deviated from normality (traditional religiosity and education) from the models would have altered the findings. The estimates were robust across model variations. We therefore report the results without exclusions and transformations but with a maximum amount donated per year of 5000 SEK (around 480 euros or 530 US dollars) as a replacement for extreme outliers. A similar approach has been used in a past research (Nilsson et al., 2016).

To test whether associations between moral foundations and personal concern with helping others depend on whether the victims belong to an in-group or an out-group, we ran mixed linear models (with maximum likelihood estimation) predicting personal charity concerns in terms of moral foundations, type of group (in-group vs. out-group) as a within-subjects factor, and the interaction between moral foundations and type of group. The results were very robust when we included random coefficients in the models (allowing the model parameters to vary across subjects). We therefore report results of mixed linear models (one for individualizing intuitions and one for binding intuitions) without any random coefficients.

We conducted all statistical analyses in SPSS 26.0. All reported tests of statistical significance are two-tailed. We adjusted the $p$-values for our tested hypotheses sequentially through Holm's (1979) modified Bonferroni procedure to avoid capitalizing on chance. These corrections did not affect any of the statistical conclusions (see Tables S7 and S8, https://osf.io/whnp4). In order to disentangle the decision to donate from the selection of a cause to allocate the donation to, we performed analyses involving allocations to in-group and out-group causes in the behavioural data with the self-selected subset of participants who had chosen to volunteer for charity $(n=584)$; all other analyses were based on the full sample $(n=985)$.

Data, codebook, and scripts for the analyses are openly accessible: 'Dataset.csv' (https://osf.io/49ehm), 'Codebook. pdf' (https://osf.io/6a9zj), 'SPSS syntax.sps' (https://osf.io/ b3ywp), and 'Mixed models.zip' (https://osf.io/8234x). For complete supporting information, see https://osf.io/ mcwv7.

\section{RESULTS}

\section{Associations between self-report and behavioural measures of charitable giving}

The results revealed a consistent association between corresponding behavioural and self-report measures of charitable giving. The behavioural measure of whether the participants chose to volunteer for charity or not was associated with the self-report measures of whether participants had donated to charity over the last year $(\phi=.17[.11, .23])$, the total amount donated $(\rho=.21[.15, .27])$, and donations to the out-group of street-begging migrants $(\rho=.11[.05, .17] ; p<.001$; $n=985)$. Among participants who chose to volunteer for charity, the behavioural measure of in-group allocations was associated with in-group (vs. out-group) allocations in the hypothetical dilemma $(r=.19[.12, .27])$, less self-reported donations to street-begging migrants ( $\rho=-.17[-.25,-.09])$, more concern for helping in Sweden $(r=.18[.10, .26])$, and less concern for helping in other countries $(r=-.29[-.36,-.21] ; p<.001)$. Out-group allocation behaviour among participants who chose to volunteer correlated with hypothetical out-group (vs. in-group) allocations ( $r=.15[.08, .23])$, self-reported donations to street-begging migrants $(\rho=.14[.06, .22])$, more concern for helping in other countries $(r=.32[.26, .39]$; $p \leq .001)$, and less concern for helping in Sweden $(r=-.10[-.18,-.02] ; p=.012 ; n=584$; the complete correlations between all measures of charitable giving are presented in Table S1, https://osf.io/whnp4).

\section{Effects on incidence and amount of donations}

\section{Moral foundations}

Consistent with our hypotheses, individualizing moral intuitions correlated positively with agreeing to volunteer for charity in behavioural data $(r=.20[.14, .26])$, with having donated last year in self-report data $(r=.17[.10, .23])$, and with higher self-reported amount of donations $(\rho=.20[.13$, $.26] ; p<.001)$. These correlations generalized across intuitions concerning harm and fairness (Table 1). Binding intuitions correlated negatively with agreeing to volunteer $(r=-.18[-.24,-.12] ; p<.001)$ and with self-reported amount of donations $(\rho=-.09[-.15,-.02] ; p=.006)$ but did not correlate with having donated in self-report data $(r=-.03[-.09, .04] ; p=.431 ; n=985)$. The correlations with volunteering generalized across in-group loyalty, authority, and purity/sanctity, while the correlation with self-reported amount of donations was driven by respect for authority and purity/sanctity (Table $1 ; n=985$ for all analyses).

\section{Political ideology, religiosity, and demographics}

Resistance to change and preference for equality were similar to binding and individualizing moral intuitions, respectively, in terms of their associations with the overall incidence and amount of donations. Just-world belief predicted less volunteering and lower self-reported amount of donations, and right-wing self-placement weakly 
predicted less volunteering. Female gender, higher age, and higher education predicted more volunteering and self-reported donations, while traditional religiosity and spirituality predicted self-reported incidence and amount of donations but not volunteering (Table $1 ; n=985$ for all analyses).

\section{All predictors}

As shown in Table 2, which presents correlations between all predictors, individualizing moral intuitions correlated with preference for equality, leftist self-placement, female gender, age, and spirituality. Binding intuitions correlated with resistance to change, just-world belief, rightist self-placement, traditional religiosity, spirituality, low preference for equality, and low education.

Odds ratios and regression coefficients from regression analyses with individualizing and binding moral intuitions, political and religious orientation, and demographic variables as predictors are shown in Table 3. These analyses revealed that higher individualizing moral intuitions, preference for equality, and education, as well as lower binding intuitions, had unique effects on choosing to volunteer for charity ( $p \leq .006$; Nagelkerke pseudo $R^{2}=.154$ and $67.5 \%$ of the cases were correctly classified). Individualizing intuitions and education independently predicted more donations in the self-report data as well, and so did traditional religiosity, age, low resistance to change $(p \leq .001)$, and to some extent right-wing self-placement $(p \leq .043$; Nagelkerke pseudo $R^{2}=.151$ and $73.1 \%$ of participants were correctly classified in terms of whether they had donated or not last year; $R^{2}=12.4 \%, R^{2}$ adj. $=11.4 \%$, for amount donated last year). The moral intuitions scales added significantly to the total variance of self-reported amount of donations accounted for over and above the effects of other predictors $\left(\Delta R^{2}=1.1 \%\right.$, $p=.002 ; n=985$ for all analyses).

The results of follow-up analyses (substituting all five foundations for individualizing and binding scores) suggested that the effects of moral foundations on overall donations were driven primarily by intuitions concerning harm and purity/sanctity $(n=985)$. The results of these analyses are shown in Table 4 (see Tables S3 and S4, https://osf.io/ whnp4, for model fit statistics).

\section{Effects on giving to in-group and out-group causes}

\section{Moral foundations}

Among participants who chose to volunteer for charity, individualizing moral intuitions correlated positively with choosing to allocate donations to an out-group organization $(r=.12[.04, .20] ; p=.005 ;$ adjusted $p=.010)$ and negatively with choosing an in-group organization $(r=-.13[-.20,-.05] ; p=.002$; adjusted $p=.006)$, while binding intuitions correlated positively with choosing an in-group organization $(r=.20[.13, .28] ; p<.001)$ and negatively with choosing an out-group organization $(r=-.19[-.27,-.11] ; p<.001 ; n=584)$. The same pattern emerged in the self-report data, with analyses based on the entire sample of participants. Individualizing intuitions correlated with higher self-reported donations

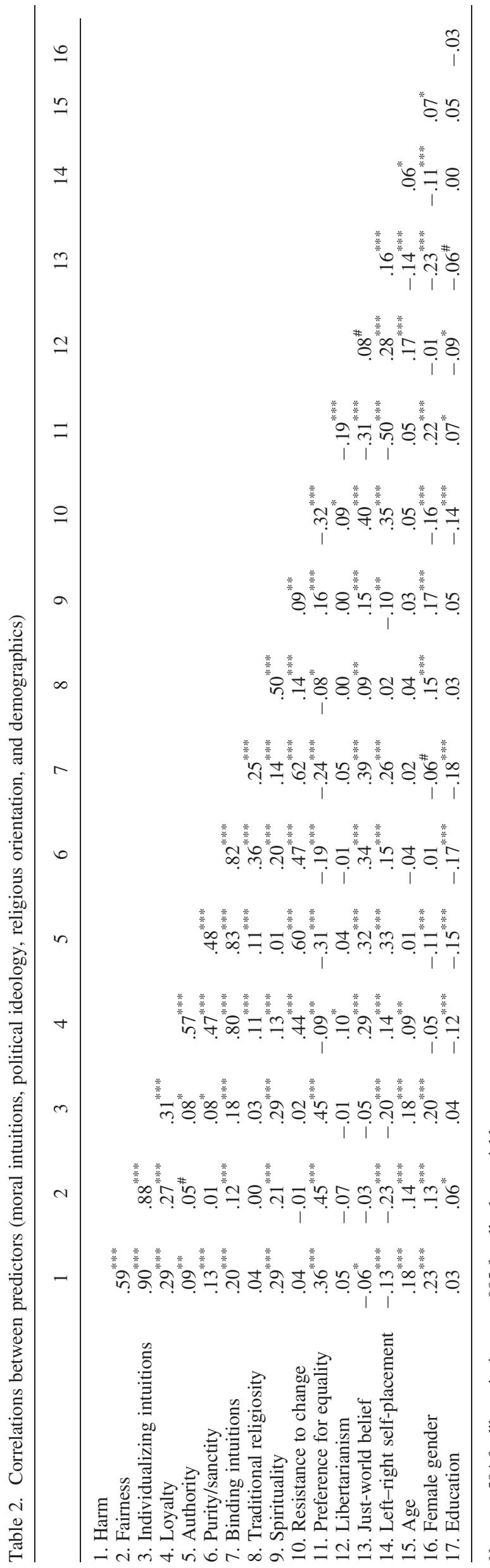


Table 3. Odds ratios based on logistic regression models and regression coefficients based on linear regression models predicting incidence and amount of donations using standardized scores

\begin{tabular}{|c|c|c|c|}
\hline & Chose to volunteer (yes/no) & Donated last year (yes/no) & Amount donated last year \\
\hline & OR $[95 \% \mathrm{CI}]$ & OR $[95 \% \mathrm{CI}]$ & $\beta[95 \% \mathrm{CI}]$ \\
\hline Individualizing intuitions & $1.50[1.26,1.79]^{* * *}$ & $1.31[1.09,1.57]^{* *}$ & $.13[.06, .21]^{* * * *}$ \\
\hline Binding intuitions & $0.68[0.56,0.83]^{* * * *}$ & $0.94[0.76,1.15]$ & $-.05[-.13, .04]$ \\
\hline Traditional religiosity & $1.11[0.94,1.30]$ & $1.28[1.06,1.55]^{* *}$ & $.12[.05, .19]^{* * * *}$ \\
\hline Spirituality & $0.98[0.83,1.16]$ & $1.14[0.95,1.36]$ & $.04[-.03, .11]$ \\
\hline Resistance to change & $0.92[0.76,1.11]$ & $0.76[0.62,0.93]^{* *}$ & $-.14[-.22,-.06]^{* * * *}$ \\
\hline Preference for equality & $1.29[1.08,1.55]^{* *}$ & $1.05[0.86,1.28]$ & $.04[-.05, .12]$ \\
\hline Just-world belief & $0.95[0.81,1.11]$ & $1.14[0.96,1.36]$ & $-.02[-.09, .05]$ \\
\hline Left-right self-placement & $1.15[0.98,1.36]^{\#}$ & $1.21[1.01,1.44]^{*}$ & $.07[.00, .14]^{*}$ \\
\hline Age & $1.10[0.96,1.26]$ & $1.54[1.32,1.79]^{* * * *}$ & $.17[.11, .23]^{* * * *}$ \\
\hline Female gender & $0.98[0.73,1.31]$ & $1.32[0.96,1.81]^{\#}$ & $-.03[-.09, .04]$ \\
\hline Education & $1.28[1.11,1.47]^{* * * *}$ & $1.28[1.11,1.49]^{* * * *}$ & $.11[.05, .17]^{* * * *}$ \\
\hline
\end{tabular}

Note: $n=985$. CI, confidence interval; OR, odds ratio.

${ }^{\#} p \leq .10 . * p \leq .05 . * * p \leq .01 . * * * p \leq .001$.

Table 4. Odds ratios based on logistic regression models and regression coefficients based on linear regression models predicting incidence and amount of donations using standardized scores

\begin{tabular}{llcc}
\hline & \multicolumn{1}{c}{ Chose to volunteer (yes/no) } & Donated last year (yes/no) & Amount donated last year \\
\cline { 2 - 4 } & \multicolumn{1}{c}{ OR $[95 \% \mathrm{CI}]$} & OR[95\% CI $]$ & $\beta[95 \% \mathrm{CI}]$ \\
\hline Harm & $1.34[1.11,1.63]^{* *}$ & $1.35[1.10,1.65]^{* * *}$ & $.16[.08, .24]^{* * *}$ \\
Fairness & $1.16[0.96,1.40]^{*}$ & $0.99[0.81,1.21]$ & $-.02[-.10, .06]$ \\
Loyalty & $0.85[0.70,1.03]^{*}$ & $1.00[0.82,1.23]$ & $.04[-.05, .12]$ \\
Authority & $1.12[0.91,1.37]^{* *}$ & $1.02[0.83,1.27]$ & $-.07[-.15, .02]$ \\
Purity/sanctity & $0.67[0.56,0.80]^{* *}$ & $0.89[0.73,1.09]^{* *}$ & $-.04[-.12, .04]$ \\
Traditional religiosity & $1.16[0.98,1.37]^{*}$ & $1.32[1.08,1.60]^{* *}$ & $.13[.06, .20]^{* * *}$ \\
Spirituality & $1.00[0.84,1.18]^{*}$ & $1.13[0.94,1.35]^{* *}$ & $.03[-.04, .10]$ \\
Resistance to change & $0.88[0.73,1.06]^{* *}$ & $0.75[0.61,0.92]^{* *}$ & $-.14[-.22,-.05]^{* * *}$ \\
Preference for equality & $1.33[1.11,1.61]^{*}$ & $1.07[0.88,1.31]$ & $.04[-.04, .12]$ \\
Just-world belief & $0.98[0.83,1.15]^{*}$ & $1.16[0.97,1.39]^{*}$ & $-.01[-.08, .06]$ \\
Left-right self-placement & $1.12[0.95,1.32]$ & $1.19[1.00,1.42]^{*}$ & $.07[.00, .14]^{*}$ \\
Age & $1.10[0.95,1.26]^{* * *}$ & $1.52[1.31,1.78]^{* * *}$ & $.17[.11, .23]^{* * *}$ \\
Female gender & $1.00[0.74,1.34]^{* * *}$ & $1.29[0.94,1.78]^{* * *}$ & $-.03[-.10, .03]$ \\
Education & $1.27[1.11,1.46]^{* *}$ & $1.29[1.11,1.49]^{* * *}$ & $.11[.05, .17]^{* * *}$ \\
\hline
\end{tabular}

Note: $n=985$. CI, confidence interval; OR, odds ratio.

${ }^{\#} p \leq .10 . * p \leq .05 . * * p \leq .01 . * * p \leq .001$.
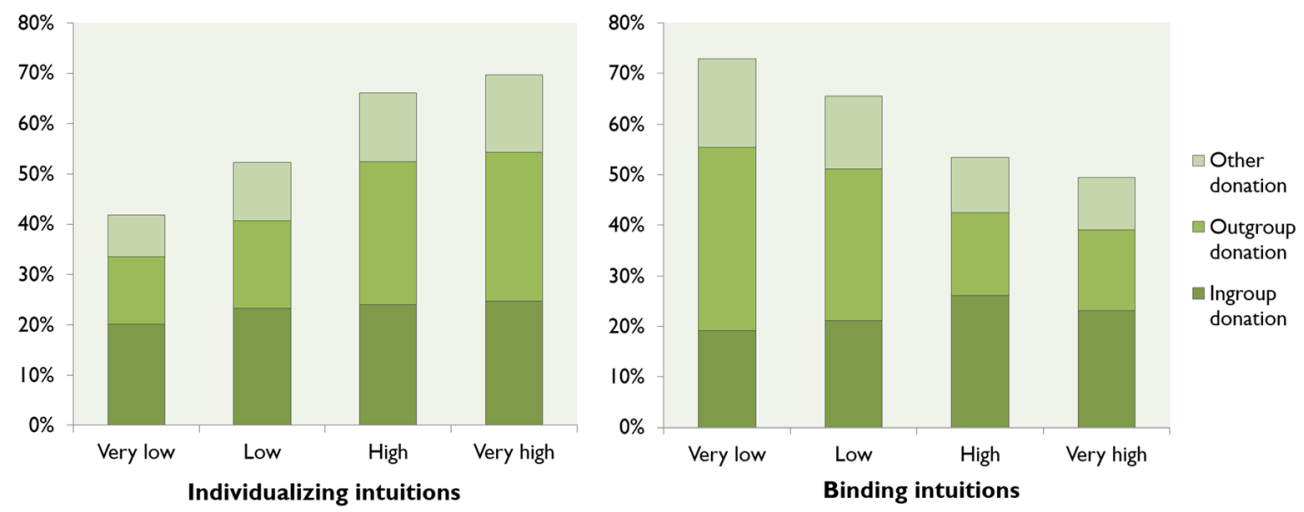

Figure 1. Percentages of participants who volunteered for charity as a function of moral intuitions. Low/high: below/above the median. Very low/very high: first/fourth quartile. [Colour figure can be viewed at wileyonlinelibrary.com]

$(\rho=.20[.14, .26] ; p<.001)$ and hypothetical allocations $(r=.23[.17, .30] ; p<.001)$ to out-group causes, while binding intuitions correlated with lower self-reported donations $(\rho=-.10[-.16,-.03] ; p=002)$ and hypothetical allocations $(r=-.23[-.29,-.16] ; p<.001 ; n=985)$ to out-group causes. These results are consistent with our 
hypotheses. The higher frequencies of volunteers and the higher ratios of out-group to in-group allocations among volunteers with higher individualizing and lower binding intuitions are illustrated in Figure 1. Follow-up analyses suggested that the results hold up across all five moral foundations, although the results were somewhat less consistent for the loyalty foundation (Table 1).

Individualizing moral intuitions also predicted more concern with helping both in Sweden $(r=.28[.22, .34])$ and in other countries $(r=.38[.32, .44])$, while binding intuitions predicted more concern with helping in Sweden $(r=.19[.14, .25])$ but less concern with helping in other countries $(r=-.12[-.19,-.06] ; p<.001)$, consistent with the notion that individualizing intuitions entail a wider moral circle than binding intuitions do. Furthermore, mixed linear models revealed that the effects of binding moral intuitions, and to some extent individualizing intuitions, on concern with helping others were moderated by what group the victims belonged to (interaction effect of individualizing intuitions and group: $\beta=.10[.02, .19], p=.014$, adjusted $p=.014$; main effect of individualizing intuitions, $\beta=.28[.22, .33], p<.001$; interaction effect of binding intuitions and group, $\beta=-.31[-.40,-.23], p<.001$; main effect of binding intuitions, $\beta=.19[.13, .26], p<.001$; $n=985$ for all these analyses). In other words, participants with individualizing intuitions expressed more concern for helping out-groups (vs. in-groups) compared with participants with less individualizing intuitions, and participants with binding intuitions expressed more concern for helping in-groups (vs. out-groups) compared with participants with less binding intuitions.

Political ideology, religious, orientation, and demographics With respect to left-right political ideology, the results were, once again, very similar to those we obtained for binding and individualizing intuitions. Resistance to change (and to some extent right-wing self-placement) predicted a preference for in-group causes, while preference for equality predicted a preference for out-group causes, and these results held up across behavioural allocations of donations among volunteers $(n=584)$ and self-report measures of in-group and out-group giving in the full sample $(n=985 ; p<.001)$. Just-world beliefs also exhibited a weak but consistent relationship with favouring in-group causes, along with less concern with helping both out-groups and in-groups, and libertarianism predicted higher allocation to an in-group in a hypothetical situation and more concern with helping an in-group (Table 1).

Spirituality was a better predictor of out-group and in-group giving than traditional religiosity, correlating with less allocations to an in-group cause among volunteers in behavioural data $(n=584)$, as well as higher donations and hypothetical allocations to an out-group, and more concern particularly with helping an out-group, in self-report data $(n=985)$. All demographic variables predicted allocation to an out-group cause weakly among participants who had chosen to volunteer for charity $(n=584)$. Female gender and education also predicted out-group giving in the self-report data in the full sample. All three demographic 
variables predicted greater concern with helping out-groups, but age and gender predicted more concern also with helping the in-group, while education predicted less concern with helping the in-group ( $n=985$; Table 1$)$.

\section{All predictors}

Odds ratios and regression coefficients from regression analyses with all predictor variables included are shown in Table 5. Among participants who chose to volunteer $(n=584)$, binding moral intuitions was the only predictor with a significant unique effect $(p=.002)$ on allocations to an in-group cause (Nagelkerke pseudo $R^{2}=.141$ and $66.1 \%$ of the cases were correctly classified), while binding moral intuitions $(p=.051)$ and resistance to change $(p=.008)$ independently predicted less allocations, and age predicted more allocations $(p=.001)$, to an out-group cause (Nagelkerke pseudo $R^{2}=.136$ and $65.4 \%$ of the cases were correctly classified). Individualizing moral intuitions and preference for equality had similar effects on in-group and out-group allocations, but neither of these effects reached significance ( $p \geq .087$; Table 5).

With respect to the hypothetical dilemma, individualizing moral intuitions $(p<.001)$, and to some extent preference for equality, left-wing self-placement, traditional religiosity, just-world belief, and education $(p \leq .035)$, independently predicted more out-group allocations, while binding moral intuitions and resistance to change independently predicted more in-group allocations $(p<.001)$ - and the two moral foundations scales contributed significantly to the variance in hypothetical allocations the model accounted for $\left(R^{2}=22.0 \%, R^{2}\right.$ adj. $\left.=21.1 \%, \Delta R^{2}=3.2 \%, p<.001\right)$. Traditional religiosity, spirituality, preference for equality, left-wing self-placement, and lower resistance to change also had unique effects on self-reported donations to an out-group $\left(p \leq .001 ; R^{2}=21.0 \%, R^{2}\right.$ adj. $=20.1 \% ; n=985$; Table 4$)$.

Both individualizing and binding moral intuitions, resistance to change, age, and female gender independently predicted higher concern with helping an in-group ( $p \leq .003)$, while just-world belief, and to some extent education and traditional religiosity, independently predicted less concern with helping an in-group $(p \leq .031)$. Individualizing moral intuitions, spirituality $(p<.001)$, and to some extent preference for equality and traditional religiosity $(p \leq .038)$ also had unique effects on higher concern with helping an outgroup, while resistance to change and right-wing selfplacement independently predicted less concern with helping an out-group $(p \leq .001)$. The moral foundations scales contributed significantly to the prediction of concern with helping both the in-group $\left(R^{2}=20.6 \%, R^{2}\right.$ adj. $=19.7 \%$, $\left.\Delta R^{2}=3.5 \%\right)$ and the out-group $\left(R^{2}=29.7 \%, R^{2}\right.$ adj. $=28.9 \%, \Delta R^{2}=5.1 \% ; p<.001 ; n=985$; see pp. $6-7$ in Supporting Information, https://osf.io/whnp4, for additional results based on structural equation modelling).

The results of follow-up analyses (replacing the individualizing and binding sum scores with the five foundations), which are shown in Table 6, suggested that the effects of moral foundations on in-group and out-group charitability were most robust across the harm and authority foundations

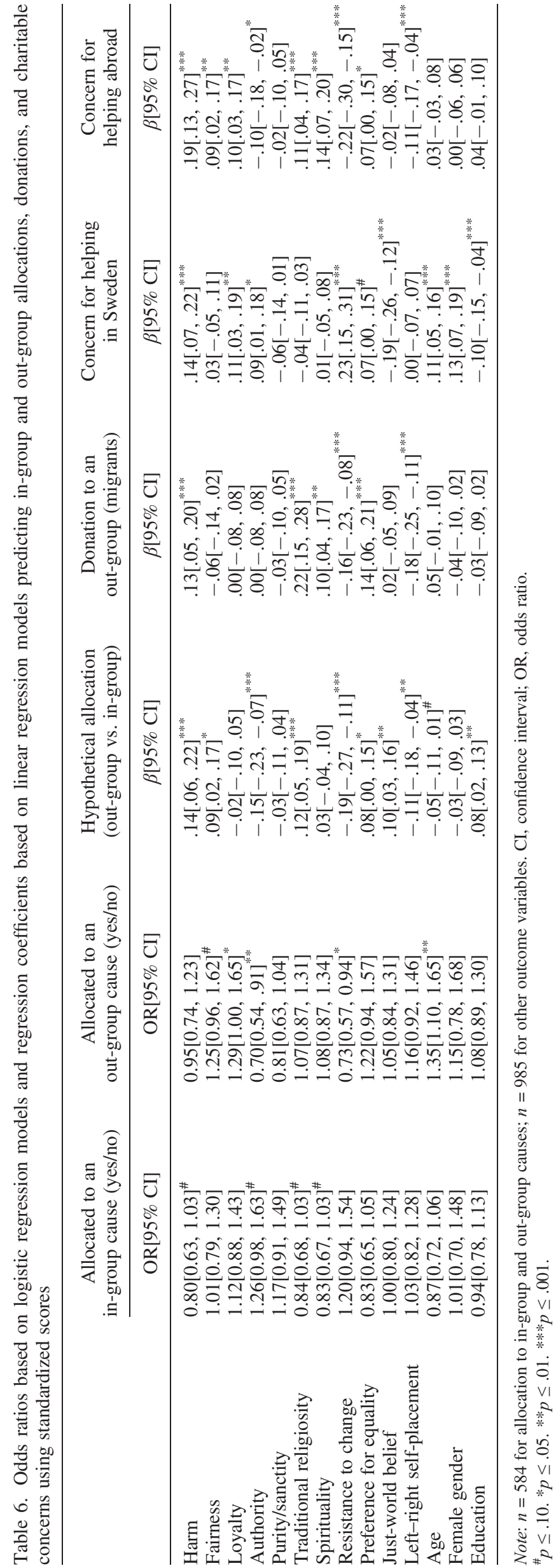

Eur. J. Pers. (2020) 
(see Tables S3 and S4, https://osf.io/whnp4, for model fit statistics).

\section{DISCUSSION}

\section{Findings and implications}

The results of this study show that moral intuitions predict both the amount and allocation of donations to charity. The more a participant expressed individualizing moral intuitions about being fair and caring for the weak and vulnerable, the more likely this participant was to comply with a request to volunteer for charity and report higher overall donations to charity, to be passionate about causes that benefit both in-group and out-group victims, and to allocate donations to out-group causes. Conversely, participants who expressed binding moral intuitions concerning loyalty, respect for authority, and purity/sanctity were less likely than participants without such intuitions to comply with a request to volunteer for charity, and they reported lower overall donations to charity, but they were more passionate about causes that potentially benefit in-group victims and tended to allocate donations to this type of causes.

These results resolve an inconsistency in past research. The fact that the binding intuitions have been found to predict lower donations to both in-group and out-group causes in behavioural data but higher donations to in-group causes in self-report data (Nilsson et al., 2016) can most likely be explained in terms of the finding that binding intuitions make people less likely to comply with donation requests. When the act of allocating resources to in-group and out-group causes was separated from the act of choosing whether to comply with the donation request or not, the binding intuitions were clearly associated with higher prioritization of in-group causes in both behavioural and self-report data.

The results are, furthermore, consistent with the account of binding and individualizing moral intuitions provided by moral foundations theory (Graham et al., 2009; Haidt, 2007, 2008). Specifically, they support the notion that the individualizing moral intuitions entail an expansion of the circle of moral engagement and a concern for the welfare of all individuals regardless of their group membership, whereas the binding moral intuitions pull the moral circle inward towards in-groups such as friends, family members, and compatriots (Graham et al., 2017). In other words, they suggest that the individualizing moral intuitions foster an impartiality with respect to in-group and out-group victims that, in turn, serves as a counterweight to moral parochialism, while the binding intuitions foster a prioritization of in-group victims.

Furthermore, exploratory analyses suggested that the moral intuitions predict charitable giving over and above the effects of political ideology, religious orientation, and demographics. Individualizing moral intuitions was the most robust of all predictors of the overall incidence and amount of donations across behavioural and self-report data, and binding moral intuitions was, together with resistance to change, the most robust predictor of allocation of donations to in-group causes.
At the same time, a few complications need to be noted with respect to the interpretation of the findings. Follow-up analyses that replaced the binding and individualizing dimensions with the five specific foundations revealed that respect for authority, and to some extent purity/sanctity, had stronger and more robust effects on charitable giving than in-group loyalty did. These results need to be interpreted with caution. It is possible that the relatively weak effects of in-group loyalty on charitable giving were simply a consequence of the low internal reliability of the loyalty scale, and it is important to keep in mind that the distinctions between different individualizing and binding foundations may not be clear-cut (Iurino \& Saucier, 2020). Nevertheless, it is also possible that the specific group that loyalty is directed at matters a great deal. The measures of in-group and out-group giving that we used focused almost exclusively on the boundary between national and international interests. The respect for authority and resistance to change scales may mainly tap into support for national traditions, norms, and authorities, and they were both strongly associated with the measures of in-group giving we used. The loyalty scale, on the other hand, includes items concerning loyalty to several different in-groups, including a nation, a team, and a family, as well as items with no specific group reference. It is possible that Swedes tend to be sensitive to what group loyalty is directed at given that in-group loyalty, particularly to national groups, is a politically sensitive topic in Sweden (Nilsson \& Erlandsson, 2015).

A second important qualification is that the moral intuitions were far from exclusive predictors of charitable giving. Particularly, political ideology paralleled moral foundations in terms of predictive power. The effects of preference for equality on charitable giving were similar to those of individualizing moral intuitions, and the effects of resistance to change, and to a lesser extent just-world beliefs and right-wing self-placement, were similar to those of the binding moral intuitions. These findings are not surprising given the substantial overlap between moral foundations and political ideology we found (see also results of structural equation modelling, pp. 6-7 in Supporting Information, https://osf.io/whnp4), nor are they necessarily inconsistent with moral foundations theory. After all, this theory was designed to capture differences in moral intuitions along the political liberal-conservative spectrum (Graham et al., 2009; Haidt \& Graham, 2007). It therefore inevitably overlaps with other theories of ideology (Duckitt, 2001; Jost et al., 2003; Schwartz et al., 2010) in terms of the dispositions it describes. Nevertheless, moral foundations theory illuminates the distinctly moral aspects of ideology and their congruence with moral behaviour, while other accounts of ideology have been tailored to serve other theoretical goals.

The results also provide further evidence of a role for demographic factors in charitable giving. Age, female gender, and education predicted the incidence and amount of donations, consistent with findings from past research (Bekkers \& Wiepking, 2011), and they were weakly associated with out-group giving as well. Education was, together with individualizing intuitions, the most robust 
predictor of overall donations across behavioural and self-report data. Age was a highly robust predictor of overall donations in self-report data and out-group allocations in behavioural data.

Finally, the results replicate the well-known finding that religiosity predicts charitable giving (Bekkers \& Wiepking, 2011; Norenzayan et al., 2013). But they also provide new insight concerning the relevance of the distinction between traditional religiosity and spirituality (Saucier \& Skrzypińska, 2006) to the psychology of charitable giving - spiritual universalism was somewhat more strongly associated with self-reported charitability towards out-groups, while traditional religiosity had more robust effects on self-report measures of charitable giving in general when all predictors were taken into consideration. Interestingly, neither traditional religiosity nor spiritual universalism was related to the behavioural measures of whether participants chose to volunteer for charity and how those who did allocated their donations. This finding provides further support for the notion that religiously based charitable giving is driven more by the number of solicitations religious donors encounter in their daily lives than by a higher than average inclination to donate whenever solicited (Bekkers \& Wiepking, 2011; Nilsson et al., 2016).

\section{Limitations and future directions}

Although the results generally point towards a convergence between self-report and behavioural measures of charitable giving, there were some key differences between the behavioural and self-report measures we used. Most notably, we measured donation behaviour in terms of the response to a single request to volunteer for charity, while several of the self-report measures tapped into aggregated monetary donations over the last year. These forms of charitable giving may be driven in part by different mechanisms. For instance, self-reported donations are influenced by the number of solicitations people encounter, and these donations are also more likely to reflect reputational concerns than volunteering in an anonymous online survey study is (see Bekkers \& Wiepking, 2011, for a review). Furthermore, volunteering is typically associated with a more emotional mindset, involving enthusiasm, empathy, happiness, and a sense of personal meaning, while donating money is, to a greater extent, associated with a sense of self-sufficiency and social distance to those in need (Lee \& Chang, 2007; Liu \& Aaker, 2008). On the other hand, it is difficult to know whether volunteering in the artificial situation of an online study reflects real-world charitable giving in these respects. In addition, it is possible that the items about libertarianism that volunteers filled out primed a concern with liberty that affected their allocation of donations.

Including behavioural measures of both volunteering and monetary donations across several different situations, preferably with high ecological validity, in future studies would help us to determine the generality of the effects of personality on charitable giving. Taking variations in the cost of donations into account would also be useful, as recent research has suggested that personality traits may have different effects on costly and costless prosociality (Ferguson, Zhao, O'Carroll, \& Smillie, 2019).

Furthermore, disentangling charitable giving (both allocations and donations) to different kinds of in-groups would be of great value. It may be particularly important to distinguish giving towards narrow circles of family and friends that the donor has personal relationships to from giving towards broader, more impersonal collectives, such as nations, gender groups, or ethnic groups. It may also be useful to investigate whether effects on giving to specific in-groups are moderated by identification with those groups. In addition, future research might address the distinction between giving to causes that provide help to human victims and giving to causes that provide help to non-human victims (e.g. animals, ecosystems, or the earth). Environmental causes may occupy a somewhat idiosyncratic position among charitable causes, as they can, to varying degrees, be directed at human or non-human victims and in-groups or out-groups. Understanding the links between personality and giving to environmentalist causes may therefore require careful categorization of these causes. ${ }^{2}$

Another general limitation of this research is that the predictors we focused on make up a selective subset of the personality domain. Moral foundations, political ideology, and religiosity do not provide a complete picture of the beliefs, values, and narratives that comprise a person's worldview, let alone of personality as whole. In general, more basic personality research is needed to develop comprehensive taxonomies of the contents of personal worldviews and compare the predictive and explanatory power of worldview constructs and more traditional trait constructs (e.g. the Big Five or the HEXACO) in a systematic manner (Nilsson, 2014). For instance, understanding why people currently rally in large numbers to 'save the earth' may require us to understand the basic beliefs people hold regarding mankind and nature (de Witt, de Boer, Hedlund, \& Osseweijer, 2016).

Further research is needed also for elucidating more fine-grained aspects of the relation between moral foundations and charitable giving (and political ideology, see Nilsson et al., 2020). In the current research, we focused on the superordinate distinction between binding and individualizing moral foundations. More work is needed to refine the model of the specific foundations underneath these superordinate dimensions (Iurino \& Saucier, 2020), contrast it with alternatives (Curry, Chesters, \& van Lissa, 2019), and investigate the associations between specific moral foundations and prosociality. Research that maps specific moral foundations to charitable causes, for instance, by framing charity appeals in terms of moral foundations (Winterich, Yinlong, \& Mittal, 2012) or by distinguishing moral concerns directed at different in-groups and out-groups (Eriksson, Simpson, \& Strimling, 2019; Voelkel \& Brandt, 2019), would be particularly useful for determining

\footnotetext{
${ }^{2}$ Moral foundations, political ideology, and religiosity had little effect on allocations to environmental causes in the current study, as shown in Table S2, https://osf.io/whnp4.
} 
the incremental validity of fine-grained models of moral intuitions.

\section{CONCLUSION}

The findings of this research show that moral intuitions have real-world consequences. They are not just self-serving narratives, and their associations with self-reported moral behaviours are not just methodological artefacts. Individualizing moral intuitions concerning fairness and harm prevention were associated with higher donations to charity, more concern with helping both in-group and out-group victims, and more allocations of donations to out-group causes. Binding moral intuitions concerning in-group loyalty, respect for authority, and purity/sanctity were associated with less donations overall, more concern with helping in-group victims, and more allocations to in-group causes. These associations were remarkably consistent across behavioural and self-report measures of charitable giving. The moral foundations predicted charitable giving over and above effects of political ideology, religiosity, and demographics, but some variables in these categories also had unique effects on charitable giving.

On a more practical level, the findings advance our knowledge of the personality characteristics and processes that shape in-group-focused and out-group-focused giving, and this knowledge is useful for helping fundraisers solicit donations. The scientific literature on philanthropy and the methods used to encourage donations today typically emphasize objective needs, urgencies, and utilities, while overlooking the subjective passions, tastes, and preferences of donors (Breeze, 2013). Research that maps the congruence between the personality characteristics of donors and their donation behaviours can potentially help fundraisers to identify and attract persons who are likely to donate to a particular cause and tailor the selection and framing of causes to the worldviews of potential donors.

\section{FUNDING}

Preparation of this manuscript was supported by The Swedish Foundation for Humanities and Social Sciences (Riksbankens Jubileumsfond; project ID: P14-0978:1) and The Swedish Research Council (Vetenskapsrådet;project ID: 2014-1158).

\section{AUTHOR CONTRIBUTIONS}

Artur Nilsson planned and performed the analyses, conceptualized the research, wrote the paper, and revised the paper. Arvid Erlandsson wasin charge of the study design, the data collection, and the construction of measures of charitable giving. Arvid Erlandsson and Daniel Västfjäll provided feedback on the conceptualization of the research, the article, andthe revision. All authors contributed to the study design.

\section{SUPPORTING INFORMATION}

Additional supporting information may be found online in the Supporting Information section at the end of the article.

Table S1. Associations between donation behavior, self-reported donations, and personal charitable concerns

Table S2. Associations between allocation to environmental causes and predictor variables

Table S3. Fit statistics of logistic regression models with different groups of predictors

Table S4. Fit statistics of hierarchical linear regression models

Table S5. Estimated effects with bias-corrected bootstrap confidence intervals (10000 resamples) in mediation analyses with concern for helping in Sweden and in other countries as mediators of the association between moral foundations and allocations to ingroup and outgroup causes Table S6. Parameter estimates of moral foundations predicting allocation of donations to ingroup and outgroup organizations

Table S7. Holm-Bonferroni corrections of $p$-values for correlation analyses

Table S8. Holm-Bonferroni corrections of $p$-values for full regression models

Data S1. Supporting Information

Data S2. Supporting Information

Open Practices Disclosure Form

\section{REFERENCES}

Aspelund, A., Lindeman, M., \& Verkasalo, M. (2013). Political conservatism and left-right orientation in 28 eastern and western European countries. Political Psychology, 34, 409-417. https:// doi.org/10.1111/pops.12000.

Balliet, D., Wu, J., \& De Dreu, C. K. W. (2014). Ingroup favoritism in cooperation: A meta-analysis. Psychological Bulletin, 140, 1556-1581. https://doi.org/10.1037/a0037737.

Batson, D. C., Kobrynowicz, D., Dinnerstein, J. L., Kampf, H. C., \& Wilson, A. D. (1997). In a very different voice: Unmasking moral hypocrisy. Journal of Personality and Social Psychology, 72, 1335-1348. https://doi.org/10.1037/0022-3514.72.6.1335.

Bekkers, R., \& Wiepking, P. (2011). Who gives? A literature review of predictors of charitable giving part one: Religion, education, age and socialisation. Voluntary Sector Review, 2, 337-365. https://doi.org/10.1332/204080511x6087712.

Bennett, R. (2003). Factors underlying the inclination to donate to particular types of charity. International Journal of Nonprofit and Voluntary Sector Marketing, 8, 12-29. https://doi.org/ 10.1002/nvsm. 198

Breeze, B. (2013). How donors choose charities: The role of personal taste and experiences in giving decisions. Voluntary Sector Review, 4, 165-183. https://doi.org/10.1332/ 204080513 X667792.

Brewer, M. B. (1979). Ingroup bias in the minimal intergroup situation: A cognitive-motivational analysis. Psychological Bulletin, 86, 307-324. https://doi.org/10.1037/0033-2909.86.2.307.

Brooks, A. C. (2007). Who really cares: The surprising truth about compassionate conservatism. New York: Basic Books.

Crimston, D., Bain, P. G., Hornsey, M. J., \& Bastian, B. (2016) Moral expansiveness: Examining variability in the extension of the moral world. Journal of Personality and Social Psychology, 111, 636-653. https://doi.org/10.1037/pspp0000086. 
Curry, O. S., Chesters, M. J., \& Van Lissa, C. J. (2019). Mapping morality with a compass: Testing the theory of 'morality-ascooperation' with a new questionnaire. Journal of Research in Personality, $\quad 78, \quad$ 106-124. https://doi.org/10.1016/j. jrp.2018.10.008.

Davies, C. L., Sibley, C. G., \& Liu, J. H. (2014). Confirmatory factor analysis of the Moral Foundations Questionnaire: Independent scale validation in a New Zealand sample. Social Psychology, 45, 431-436. https://doi.org/10.1027/1864-9335/ a000201.

Day, M. V., Fiske, S. T., Downing, E. L., \& Trail, T. E. (2014). Shifting liberal and conservative attitudes using moral foundations theory. Personality and Social Psychology Bulletin, 40, 1559-1573. https://doi.org/10.1177/ 0146167214551152.

De Witt, A., de Boer, J., Hedlund, N., \& Osseweijer, P. (2016). A new tool to map the major worldviews in the Netherlands and USA, and explore how they relate to climate change. Environmental Science \& Policy, 63, 101-112. https://doi.org/10.1016/ j.envsci.2016.05.012.

Duckitt, J. (2001). A dual-process cognitive-motivational theory of ideology and prejudice. Advances in Experimental Social Psychology, 33, 41-113. https://doi.org/10.1016/S0065-2601 (01)80004-6

Ellemers, N., van der Toorn, J., Paunov, Y., \& van Leeuwen, T. (2019). The psychology of morality: A review and analysis of empirical studies published from 1940 through 2017. Personality and Social Psychology Review, 23, 332-366. https://doi.org/ 10.1177/1088868318811759.

Eriksson, K., Simpson, B., \& Strimling, P. (2019). Political double standards in reliance on moral foundations. Judgment and Decision making, 14, 440-454.

Erlandsson, A., Björklund, F., \& Bäckström, M. (2017). Choicejustifications after allocating resources in helping dilemmas. Judgment and Decision making, 12, 60-80.

Erlandsson, A., Nilsson, A., Tinghög, A., Andersson, D., \& Västfjäll, D. (2019). Donations to outgroup charities, but not ingroup charities, predict intentions toward street-beggars in Sweden. Nonprofit and Voluntary Section Quarterly, 48, 814-838. https://doi.org/10.1177/0899764018819872.

Erlandsson, A., Nilsson, A., Tinghög, G., \& Västfjäll, D. (2018). Bullshit-sensitivity predicts prosocial behavior. PLOS ONE, 13, e0201474. https://doi.org/10.1371/journal.pone.0201474.

Everett, J. A. C., Faber, N. S., \& Crockett, M. (2015). Preferences and beliefs in ingroup favoritism. Frontiers in Behavioral Neuroscience, 9. https://doi.org/10.3389/fnbeh.2015.00015

Faul, F., Erdfelder, E., Lang, A.-G., \& Buchner, A. (2007). G*power 3: A flexible statistical power analysis program for the social, behavioral, and biomedical sciences. Behavior Research Methods, 39, 175-191. https://doi.org/10.3758/ BF03193146.

Federico, C. M., Weber, C. R., Ergun, D., \& Hunt, C. (2013). Mapping the connections between political and morality: The multiple sociopolitical orientations involved in moral intuition. Political Psychology, 34, 589-610. https://doi.org/10.1111/pops.12006.

Feinberg, M., \& Willer, R. (2013). The moral roots of environmental attitudes. Psychological Science, 24, 56-62. https://doi.org/ 10.1177/0956797612449177.

FeldmanHall, O., Mobbs, D., Evans, D., Hiscox, L., Navrady, L., \& Dalgleish, T. (2012). What we say and what we do: The relationship between real and hypothetical moral choices. Cognition, 123, 434-441. https://doi.org/10.1016/j.cognition.2012.02.001.

Ferguson, E., Zhao, K., O'Carroll, R. E., \& Smillie, L. D. (2019). Costless and costly prosociality: Correspondence among personality traits, economic preferences, and real-world prosociality. Social Psychological and Personality Science, 10, 461-471. https://doi.org/10.1177/1948550618765071.

Furnham, A. (1995). The just world, charitable giving and attitudes to disability. Personality and Individual Differences, 19, 577-583. https://doi.org/10.1016/0191-8869(95)00090-S
Graham, J., \& Haidt, J. (2010). Beyond beliefs: Religions bind individuals into moral communities. Personality and Social Psychology Bulletin, 14, 140-150. https://doi.org/10.1177/ 1088868309353415.

Graham, J., Haidt, J., Koleva, S., Motyl, M., Iyer, R., Wojcik, S. P., \& Ditto, P. H. (2013). Moral foundations theory: The pragmatic validity of moral pluralism. Advances in Experimental Social Psychology, 47, 55-130. https://doi.org/10.1016/B978-0-12407236-7.00002-4.

Graham, J., Haidt, J., \& Nosek, B. A. (2009). Liberals and conservatives rely on different sets of moral foundations. Journal of Personality and Social Psychology, 82, 1029-1046. https://doi. org/10.1037/a0015141.

Graham, J., Nosek, B. A., Haidt, J., Iyer, R., Koleva, S., \& Ditto, P. H. (2011). Mapping the moral domain. Journal of Personality and Social Psychology, 101, 366-385. https://doi.org/10.1037/ a0021847.

Graham, J., \& Valdesolo, P. (2018). Morality. In K. Deaux, \& M. Snyder (Eds.), The Oxford handbook of personality and social psychology (pp. 317-342). Oxford, UK: Oxford University Press.

Graham, J., Waytz, A., Meindl, P., Iyer, R., \& Young, L. (2017). Centripetal and centrifugal forces in the moral circle: Competing constraints on moral learning. Cognition, 167, 58-65. https://doi. org/10.1016/j.cognition.2016.12.001.

Grey Matter Research (2011, June 6). Religious Americans often do not support specifically religious charitable causes. Retrieved from http://www.greymatterresearch.com/index_files/Causes.htm

Haidt, J. (2007). The new synthesis in moral psychology. Science, 316, 998-1002. https://doi.org/10.1126/science.1137651.

Haidt, J. (2008). Morality. Perspectives on Psychological Science, 3, 65-72. https://doi.org/10.1111/j.1745-6916.2008.00063.x.

Haidt, J., \& Graham, J. (2007). When morality opposes justice: Conservatives have moral intuitions that liberals may not recognize. Social Justice Research, 20, 98-116. https://doi.org/ 10.1007/s11211-007-0034-z.

Haidt, J., \& Joseph, C. (2004). Intuitive ethics: How innately prepared intuitions generate culturally variable virtues. Daedalus, 133, 55-66. https://doi.org/10.1162/0011526042365555.

Hawkins, C. B., \& Nosek, B. A. (2012). When ingroups aren't "in": Perceived political belief similarity moderates religious ingroup favoritism. PLoS ONE, 7, e50945. https://doi.org/10.1371/journal.pone.0050945.

Holm, S. (1979). A simple sequentially rejective multiple test procedure. Scandinavian Journal of Statistics, 6, 65-70. https://doi. org/10.2307/4615733.

Iurino, K., \& Saucier, G. (2020). Testing measurement invariance of the moral foundations questionnaire across 27 countries. Assessment, 27, 365-372. https://doi.org/10.1177/1073191118817916.

Janoff-Bulman, R. (1989). Assumptive worlds and the stress of traumatic events: Applications of the schema construct. Social Cognition, 7, 113-136. https://doi.org/10.1521/ soco.1989.7.2.113.

Johansson-Stenman, O., \& Svedsäter, H. (2012). Self-image and valuation of moral goods: Stated versus actual willingness to pay. Journal of Economic Behavior \& Organization, 84, 879-891. https://doi.org/10.1016/j.jebo.2012.10.006.

Jost, J. T., Glaser, J., Kruglanski, A. W., \& Sulloway, F. J. (2003). Political conservatism as motivated social cognition. Psychological Bulletin, 129, 339-375. https://doi.org/10.1037/00332909.129.3.339.

Kahan, D. M. (2012). Cultural cognition as a conception of the cultural theory of risk. In S. Roeser, R. Hillerbrand, P. Sandin, \& M. Peterson (Eds.), Handbook of risk theory (pp. 725-759). Amsterdam, Netherlands: Springer.

Kemmelmeier, M., Jambor, E. E., \& Letner, J. J. (2006). Individualism and good works: Cultural variation in giving and volunteering across the United States. Journal of Cross-Cultural Psychology, 37, 327-344. https://doi.org/ $10.1177 / 0022022106286927$. 
Lee, Y.-K., \& Chang, C.-T. (2007). Who gives what to charity? Characteristics affecting donor behavior. Social Behavior and Personality: An International Journal, 35, 1173-1180. https:// doi.org/10.2224/sbp.2007.35.9.1173.

Liu, W., \& Aaker, J. (2008). The happiness of giving: The time-ask effect. Journal of Consumer Research, 35, 543-557. https://doi. org/10.1086/588699.

Neumayr, M., \& Handy, F. (2019). Charitable giving: What influences donors' choice among different causes? VOLUNTAS: International Journal of Voluntary and Nonprofit Organizations, 30, 783-799. https://doi.org/10.1007/s11266-017-9843-3.

Nilsson, A. (2014). Personality psychology as the integrative study of traits and worldviews. New Ideas in Psychology, 32, 18-32. https://doi.org/10.1016/j.newideapsych.2013.04.008.

Nilsson, A., \& Erlandsson, A. (2015). The moral foundations taxonomy: Structural validity and relation to political ideology in Sweden. Personality and Individual Differences, 76, 28-32. https://doi.org/10.1016/j.paid.2014.11.049.

Nilsson, A., Erlandsson, A., \& Västfjäll, D. (2016). The congruency between moral foundations and intentions to donate, self-reported donations, and actual donations to charity. Journal of Research in Personality, 65, 22-29. https://doi.org/10.1016/j.jrp.2016. 07.001 .

Nilsson, A., Erlandsson, A., \& Västfjäll, D. (2019). The complex relation between receptivity to pseudo-profound bullshit and political ideology. Personality and Social Psychology Bulletin, 45, 1440-1450. https://doi.org/10.1177/0146167219830415.

Nilsson, A. \& Jost, J. T. (2017, November 4). Rediscovering Tomkins' polarity theory: Humanism, normativism, and the bipolar structure of left-right ideology in the US and Sweden. http:// doi.org/10.17605/osf.io/9zbq3

Nilsson, A., Montgomery, H., Dimdins, G., Sandren, M., Erlandsson, A., \& Taleny, A. (2020). Beyond 'liberals' and 'conservatives': Complexity in ideology, moral intuitions, and worldview among Swedish voters. European Journal of Personality. https://doi.org/10.1002/per.2249.

Norenzayan, A., Henrich, J., \& Slingerland, E. (2013). Religious prosociality: A synthesis. In P. J. Richerson, \& M. H. Christiansen (Eds.), Cultural evolution: Society, technology, language, and religion (pp. 365-380). Cambridge, MA: MIT Press.

Piedmont, R. L. (1999). Does spirituality represent the sixth factor of personality? Spiritual transcendence and the five-factor model. Journal of Personality, 67, 985-1013. https://doi.org/10.1111/ 1467-6494.00080.

Piurko, Y., Schwartz, S. H., \& Davidov, E. (2011). Basic personal values and the meaning of left-right political orientations in 20 countries. Political Psychology, 32, 537-561. https://doi.org/ 10.1111/j.1467-9221.2011.00828.x.

Saucier, G., \& Skrzypińska, K. (2006). Spiritual but not religious? Evidence for two independent dispositions. Journal of Personality, 74, 1257-1292. https://doi.org/10.1111/j.14676494.2006.00409.x.
Schwartz, S. H., Caprara, G. V., \& Vecchione, M. (2010). Basic personal values, core political values, and voting: A longitudinal analysis. Political Psychology, 31, 421-452. https://doi.org/ 10.1111/j.1467-9221.2010.00764.x.

Silver, J. R. (2017). Moral foundations, intuitions of justice, and the intricacies of punitive sentiment. Law \& Society Review, 51, 413-450. https://doi.org/10.1111/lasr.12264.

Singer, P. (2009). The life you can save: Acting now to end world poverty. New York: Random House.

Srnka, K. J., Grohs, R. \& Eckler, I. (2003). Increasing fundraising efficiency by segmenting donors. Australasian Marketing Journal, 11, 70-86. https://doi.org/10.1016/S1441-3582(03) 70119-0

Statistics Sweden (2018). Population statistics. Retrieved from http://www.scb.se/en/finding-statistics/statistics-by-subject-area/ population/population-composition/population-statistics/

Stürmer, S., Snyder, M., Kropp, A., \& Siem, B. (2006). Empathymotivated helping: The moderating role of group membership. Personality and Social Psychology Bulletin, 32, 943-956. https://doi.org/10.1177/0146167206287363.

Tajfel, H., \& Turner, J. C. (1979). An integrative theory of intergroup conflict. In W. G. Austin \& S. Worchel (Eds.), The social psychology of intergroup relations. (pp. 33-47). Monterey, CA: Brooks/Cole.

Telzer, E. H., Ichien, N. T., \& Qu, Y. (2015). The ties that bind: Group membership shapes the neural correlates of in-group favoritism. NeuroImage, 115, 42-51. https://doi.org/10.1016/j. neuroimage.2015.04.035.

Voelkel, J. G., \& Brandt, M. J. (2019). The effect of ideological identification on the endorsement of moral values depends on the target group. Personality and Social Psychology Bulletin, 45, 851-863. https://doi.org/10.1177/0146167218798822.

Waytz, A., Iyer, R., Young, L., Haidt, J., \& Graham, J. (2019). Ideological differences in the expanse of the moral circle. Nature Communications, 10, 4389. https://doi.org/10.1038/s41467-01912227-0.

Wiepking, P. (2010). Democrats support international relief and the upper class donates to art? How opportunity, incentives and confidence affect donations to different types of charitable organizations. Social Science Research, 39, 1073-1087. https://doi.org/ 10.1016/j.ssresearch.2010.06.005.

Wiepking, P., \& Bekkers, R. (2012). Who gives? A literature review of predictors of charitable giving. Part Two: Gender, family composition and income. Voluntary Sector Review, 3, 217-245. https://doi.org/10.1332/204080512X649379.

Winterich, K. P., Yinlong, Z., \& Mittal, V. (2012). How political identity and charity positioning increase donations: Insights from moral foundations theory. International Journal of Research in Marketing, 29, 346-354. https://doi.org/10.1016/j.ijresmar. 2012.05.002.

Zagefka, H., \& James, T. (2015). The psychology of charitable donations to disaster victims and beyond. Social Issues and Policy Review, 9, 155-192. https://doi.org/10.1111/sipr.12013. 